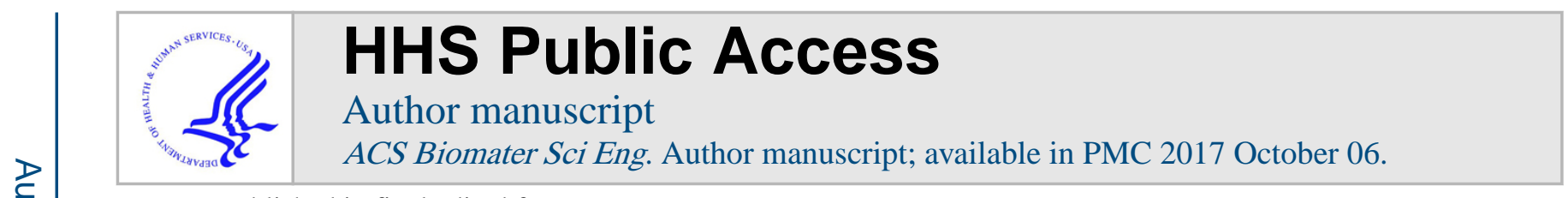

Published in final edited form as:

ACS Biomater Sci Eng. 2017 April 10; 3(4): 496-501. doi:10.1021/acsbiomaterials.7b00148.

\title{
Display of DNA on Nanoparticles for Targeting Antigen Presenting Cells
}

\author{
Nicholas M. Molino ${ }^{1, \S}$, Medea Neek ${ }^{1, \S}$, Jo Anne Tucker², Edward L. Nelson ${ }^{2,3,4}$, and Szu- \\ Wen Wang ${ }^{1,3,5,{ }^{*}}$ \\ ${ }^{1}$ Department of Chemical Engineering and Materials Science, University of California, Irvine, CA \\ 92697 USA \\ 2Department of Medicine, University of California, Irvine, CA 92697 USA \\ ${ }^{3}$ Chao Family Comprehensive Cancer Center, University of California, Irvine, CA 92697 USA \\ ${ }^{4}$ Institute for Immunology, University of California, Irvine, CA 92697 USA \\ ${ }^{5}$ Department of Biomedical Engineering, University of California, Irvine, CA 92697 USA
}

\begin{abstract}
Efficient delivery of antigens is of paramount concern in immunotherapies. We aimed to target antigen presenting cells (APCs) by conjugating $\mathrm{CpG}$ oligonucleotides to an $\mathrm{E} 2$ protein nanoparticle surface (CpG-PEG-E2). Compared to E2 alone, we observed 4-fold increase of in vitro APC uptake of both CpG-PEG-E2 and E2 conjugated to non-CpG DNA. Furthermore, compared to E2-alone or E2 functionalized solely with polyethylene glycol (PEG), the CpG-PEGE2 showed enhanced lymph node retention up to at least $48 \mathrm{hr}$ and 2-fold increase in APC uptake in vivo, parameters which are advantageous for vaccine success. This suggests that enhanced APC uptake of nanoparticles mediated by oligonucleotide display may help overcome delivery barriers in vaccine development.
\end{abstract}

\section{Graphical abstract}

\footnotetext{
*Address correspondence to: Szu-Wen Wang, Department of Chemical Engineering and Materials Science, University of California, Irvine, 916 Engineering Tower, Irvine, CA 92697-2575, wangsw@uci.edu.

$\S$ These authors contributed equally to this manuscript and are considered co-first authors.

Supporting Information

Materials, methods, and additional data, including those for nanoparticle characterization, nanoparticle uptake, DEC-205 expression, uptake inhibition, and in vivo biodistribution.
} 


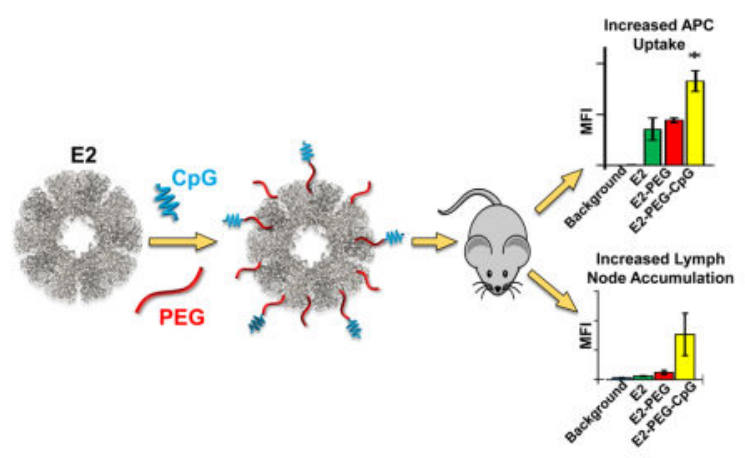

\section{Keywords}

CpG; oligonucleotide; dendritic cell targeting; polyethylene glycol; nanoparticle vaccine; E2; biodistribution

Though improved surgery, chemotherapy, and radiation techniques should endure in the toolbox of oncologic interventions, ${ }^{1}$ immunotherapies have emerged as a revolutionary approach in cancer treatment, sprouting from an increased understanding of cancer biology, the human genome, and the immune system. ${ }^{2}$ Cancer immunotherapies engage one's own immune system for targeted tumor destruction, eradication of metastases, and production of immunological memory. Cancer vaccines have long been a strategy to elicit anti-tumor immunity. Among the many challenges facing the design of a cancer vaccine is an optimal delivery method. ${ }^{2}$

The ability to supply sufficient amounts of antigen and immune-modulating compounds to the lymphatics is critical, ${ }^{3}$ and more specifically delivery to professional antigen presenting cells (APCs), such as dendritic cells (DCs) that are responsible for orchestration of the adaptive anti-cancer response. ${ }^{4}$ Engineered biomaterials, and in particular those that are nanostructured, ${ }^{5}$ represent technologies that may help to overcome antigen delivery problems. ${ }^{6}$ Nanoparticles naturally access lymphatics following immunization and interact with DCs and other APCs, ${ }^{3}$ which may be enhanced by displaying DC-specific antibodies. ${ }^{7-9}$ While antibodies are tremendously specific to their target, they can be difficult to produce and would likely significantly alter the physical size and properties of the nanoparticle vaccine platform. ${ }^{7}$

Ideally, a simple-to-employ DC-specific targeting moiety would be preferred for biomaterial design. Recently, the Toll-like receptor (TLR) 9 agonist CpG (single-stranded nonmethylated oligodeoxynucleotides containing CG motifs) was revealed as a possible ligand for DEC-205, an endocytic receptor expressed mainly by DCs and other APCs. ${ }^{10}$ The finding that DCs may possess receptors to detect CpG-containing single stranded DNA (ssDNA) presents the opportunity to exploit a naturally occurring TLR ligand that may also serve as an APC-targeting molecule for vaccine delivery.

Our group has been developing the pyruvate dehydrogenase-derived, self-assembling (60mer) E2 caged protein nanoparticle for biomedical applications, including cancer 
immunotherapy. ${ }^{11-16}$ We have shown that E2 possesses the capability to simultaneously deliver tumor antigens and $\mathrm{CpG}$ to DCs for enhanced activation of antigen-specific CD8+ T cells, yielding enhanced anti-cancer activity and increased survival time of syngeneic tumorbearing mice. ${ }^{12,14}$

Caged protein nanoparticles (e.g., E2, virus-like particles [VLPs]) exhibit unique advantages over other nanoparticles for immunotherapy, ${ }^{17-18}$ in that they represent a geneticallymodifiable homogenous platform that also exhibits a natural tropism and the optimal geometry for interaction with APCs in situ. $3,17,19$ Though E2 has been successfully applied in a murine model, demonstrating strong potential in cancer immunotherapy development, ${ }^{12,} 14$ the in vivo fate of this platform has not been elucidated. In this study, our goals were to examine the biodistribution of the E2 nanoparticle vaccine platform, and in particular to investigate whether CpG display on E2 could increase affinity for DCs in secondary lymphoid organs.

E2 nanoparticles were conjugated with green fluorescent dye through non-native internal cavity cysteines (E2 mutant D381C, herein simply abbreviated "E2"), in order to facilitate tracking. ${ }^{11}$ For ligand display, we conjugated $5^{\prime}$ thiol-terminated CpG 1826 or non-CpG ssDNA oligodeoxynucleotide 1982 to solvent-exposed lysines on the E2 nanoparticle surface via a bifunctional amine- and thiol-reactive poly(ethylene glycol) (PEG; average molecular weight $2000 \mathrm{Da}$ ) linker. CpG 1826 is known to activate DCs, while non-CpG 1982 has served as a negative control for such prior studies. ${ }^{20-23}$ These nanoparticles are abbreviated CpG-PEG-E2 and (non-CpG)-PEG-E2, respectively. Methoxy-terminated amine-reactive PEG conjugated to the surface-accessible lysines on E2 served as a control devoid of DNA (mPEG-E2; average PEG molecular weight of 2000 Da) (See Methods in Supporting Information). We have previously shown that surface-bound 2000 Da PEG can inhibit cellular interaction with E2 and may serve as a flexible linker to facilitate ligand/ receptor interaction on cells. ${ }^{13}, 16$ PEG linkers larger than 2000 Da have been shown to increase nanoparticle size and polydispersity. ${ }^{8}$

We characterized our functionalized $\mathrm{E} 2$ to ensure that external conjugation of $\mathrm{CpG}$ did not significantly alter E2 size or cause aggregation (Figure 1). SDS-PAGE of functionalized E2 nanoparticles revealed protein between $\sim 30-40 \mathrm{kDa}$ for mPEG-E2, consistent with heterogeneous attachment of one or more $2000 \pm 200$ Da PEGs per E2 subunit (Figure S1). For the CpG-PEG-E2 and (non-CpG)-PEG-E2 samples, bands were observed at $\sim 28 \mathrm{kDa}$ (consistent with E2, no conjugation), $\sim 30-32 \mathrm{kDa}$ (E2 + PEG, no attached $\mathrm{CpG}$ ), and $\sim 35$ $\mathrm{kDa}(\mathrm{E} 2+\mathrm{PEG}+\mathrm{CpG})$, supporting a 60 -mer particle with varying degrees of conjugation. Bands at $\sim 60 \mathrm{kDa}$ and above are artifacts that are consistently observed when conjugating the bifunctional PEG linker with E2, ${ }^{16}$ and this control is shown in the lane of malPEG-E2 (Figure S1). Unreacted maleimides were quenched with L-cysteine. We estimated a conjugation ratio of $16 \pm 5 \mathrm{CpG} / \mathrm{E} 2$ nanoparticle (Supporting Information), within the range achieved for a synthetic nanoparticle system, when adjusting for the difference in particle diameter. ${ }^{24}$ Depending on the conformation of the PEG (i.e. brush or mushroom), the polymer may not be fully extended and the maleimide may not be easily accessible to react with the thiol-terminated $\mathrm{CpG}^{25}$ 
Dynamic light scattering (DLS) revealed no significant changes in average particle sizes (Figure 1), demonstrating that conjugation of PEG and ssDNA to E2 did not cause large increases in particle size or aggregation. Zeta potential measurements showed modest shifts in nanoparticle surface charge, relative to $-12 \pm 1 \mathrm{mV}$ for bare E2 (Figure 1; Methods in Supporting Information). Furthermore, the measured increase in negative surface charge of ssDNA-containing E2, relative to the more neutral PEGylated E2, is consistent with surface conjugation of DNA.

We examined the in vitro association of the fluorescently-labeled nanoparticles (E2, PEGylated E2 [mPEG-E2], CpG conjugated to E2 [CpG-PEG-E2], and non-CpG ssDNA conjugated to $\mathrm{E} 2$ [(non-CpG)-PEG-E2]) with different representative cell types, including bone marrow-derived DCs (BMDCs), bone marrow-derived macrophages (BMDMs), B cells (CH12), T cells (B3Z), and fibroblasts (NIH 3T3). As expected, PEGylation (mPEG-E2) decreased uptake of E2 by all cell types tested in vitro, relative to non-functionalized E2 (Figure 2), at multiple concentrations (Figure S2); this decrease is consistent with observations from our previously published reports and with PEGylation of other VLPs. ${ }^{13,}{ }^{26}$ CpG-PEG-E2 exhibited increased association with APCs relative to nonfunctionalized E2 ( 4-fold increase by BMDCs and BMDMs [p < 0. 001], and to a lesser extent by B cells), but not with $\mathrm{T}$ cells or fibroblasts. Trypsinization (to remove surface bound proteins) revealed that the majority of CpG-PEG-E2 nanoparticles were internalized by BMDCs and BMDMs, but not by B cells (Figure S3). We also observed enhanced BMDC and BMDM uptake of E2 conjugated with non-CpG-containing ssDNA (Figure 2), which was an unexpected result; however, this may not be too unusual given that certain cell receptors, such as DEC-205, have also shown affinity for both CpG and DNA sequences without CpG. ${ }^{10}$

While we expected increased CpG-PEG-E2 uptake by DEC-205 ${ }^{+}$BMDC (DEC-205 expression in Figure S4), which we did observe (Figure 2), it is also notable that there was increased binding to DEC-205- BMDMs. It does make sense, however, that APCs likely possess multiple external sensing mechanisms for ssDNA, such as scavenger receptors, ${ }^{27-28}$ although isolating and identifying each receptor involved is beyond the scope of the current study. In fact, examination of CpG-PEG-E2 uptake revealed involvement of both clathrinmediated uptake and macropinocytosis, consistent with multiple mechanisms, whereas uptake of E2 alone involved clathrin- and actin-mediated endocytosis (Figure S5). Sensing of TLR danger signals is known to transiently increase the macropinocytic activity of DCs, ${ }^{29}$ consistent with our observation of increased involvement of this uptake pathway toward CpG-PEG-E2, although such a phenomenon is unlikely to explain enhanced uptake of nonCpG ssDNA. Other effects, such as increased APC uptake of negatively-charged nanoparticles, has also been demonstrated, although the relatively small degree of our charge differences is unlikely to solely account for the large differences in uptake observed between our CpG-PEG-E2 and E2 nanoparticles. ${ }^{30-31}$ In any case, these results are the first, to our knowledge, to demonstrate significantly increased uptake by DCs and macrophages of nanoparticles functionalized with immunologically-relevant ssDNA oligonucleotides, critical for increasing efficacy of modern vaccines for disease like cancer. ${ }^{4}$ 
We then investigated whether the observed in vitro targeting effect mediated by display of ssDNA was evident in vivo in areas of high APC-activity (i.e., lymph nodes) by measuring fluorescence (MFI) of cells from individual organs. Six hours following subcutaneous administration (SC) in mice, the E2 nanoparticle was predominantly detected at the injection site, within the lymph nodes (LNs) ipsilateral to injection site, and to a lesser extent in the liver and spleen (Figure 3 and Figure S6). Further inspection revealed the E2 nanoparticle was found in 5 out of 7 LNs tested (injection site ipsilateral popliteal, inguinal, axillary, iliac, and renal, but not ipsilateral cervical or mesenteric; Figure 3). E2, mPEG-E2, and CpG-PEG-E2 were undetectable in the thymus, kidney, heart, and lung (Figure S6). Due to the similarity between cellular uptake data for CpG-PEG-E2 and (non-CpG)-PEG-E2 nanoparticles in vitro, only the former ssDNA-containing nanoparticle was examined in vivo. PEGylation (mPEG-E2) and CpG display (CpG-PEG-E2) on E2 exhibited a few notable changes in their in vivo fate, in that CpG-PEG-E2 was the only nanoparticle not detectable in the spleen (Figure 3) and mPEG-E2 was measured in the blood (Figure S6) and in the contralateral lymph nodes (Figure S7). Remarkably, 48 hours following administration, CpG-PEG-E2 nanoparticle was still evident in the ipsilateral dLNs (Figure 3), whereas E2 and mPEG-E2 were largely undetectable.

These observations indicated that a PEGylated surface alone allows the E2 nanoparticle to disperse further throughout the lymphatic and circulatory system, in agreement with the accepted properties of PEGylation in drug delivery systems, ${ }^{33}$ including VLPs. ${ }^{34-35}$ Display of $\mathrm{CpG}$ on the distal end of a PEG-linker (CpG-PEG-E2) resulted in retention of the E2 nanoparticle within proximal areas that contain DC populations, an attractive quality for vaccine design and success. ${ }^{36-37}$ While CpG-PEG-E2 was not detected in the spleen, the draining LNs (dLNs) have been shown to play the more critical role in acute anti-viral and anti-cancer responses. ${ }^{38}$

To determine whether accumulation and retention of CpG-PEG-E2 nanoparticles within the dLNs was due to increased affinity for cells expressing DEC-205, we more closely examined fluorescence of DEC-205+ dLN cells (i.e., popliteal, inguinal, axillary, iliac, and renal LNs ipsilateral to injection site). However, consistent with our in vitro data, we observed no significant difference between the average fluorescence of DEC-205 ${ }^{+}$cells from mice injected with CpG-PEG-E2, compared to E2 or mPEG-E2, after either 6 or 48 hours (Figure 4A, 4B).

Interestingly, however, the overall $\mathrm{CD} 11 \mathrm{c}^{+}$population (primarily DCs) from the $\mathrm{dLNs}$ of the CpG-PEG-E2 group showed a significant two-fold increased fluorescence compared to groups injected with E2 or mPEG-E2 nanoparticles (Figure 4C). This indicates increased broad DC association/uptake of CpG-PEG-E2, critically important for cell-mediated vaccine success, ${ }^{4}$ and in good agreement with our in vitro observations (Figure 2 and Figure S2). We also observed a modest increase in CpG-PEG-E2 fluorescence of $\mathrm{F} 4 / 80^{+}$cells, compared to groups given E2 or mPEG-E2 (Figure 4C). Altogether, our in vivo data suggests that decoration of the $\mathrm{E} 2$ nanoparticle with $\mathrm{CpG}$ oligonucelotides enhances physical association and/or uptake by DCs and macrophages within the dLNs following SC injection. 
Of the total $\mathrm{CD} 11 \mathrm{c}^{+}$(primarily DCs) and $\mathrm{F} 4 / 80^{+}$(macrophages and Langerhans DCs) cell populations from the dLNs, $~ 50 \%$ of were associated with E2, mPEG-E2, and CpG-PEGE2 (Figure S8), a relatively high percentage compared to other nanoparticle studies, including other VLPs. ${ }^{39-40}$ All of the E2 nanoparticles tested were also associated, although to a much lesser extent, with $\mathrm{CD}^{+}{ }^{+}$( $\mathrm{T}$ cells) and $\mathrm{B} 220^{+}$cells (B cells and plasmacytoid DCs), but interestingly showed no differences in cellular association based on surface chemistry (Figure S8). These results demonstrated that decoration of E2 with CpG (or PEG) did not significantly alter specificity for any particular cell type. Rather, a likely explanation for our observed increase in LN fluorescence of CpG-PEG-E2-injected mice may be due to general elevated overall nanoparticle uptake (Figure 4C). In any case, there appears to be a clear advantage for the delivery of E2 nanoparticles decorated externally with $\mathrm{CpG}$ molecules, from the metric of increased in vivo LN retention (Figure 3) and APC association (Figure $4 \mathrm{C}$ ), which are attractive qualities of a cancer vaccine delivery system. ${ }^{36-37}$

Here, we have demonstrated that surface display of CpG-containing ssDNA oligonucleotides significantly increased APC-specific uptake of the E2 nanoparticle. In vitro ssDNA decoration induced large increases in cellular uptake of E2 by DCs, macrophages, and B cells. In vivo, the CpG-PEG-E2 nanoparticle showed a significant increase in cellular association with DCs within the dLNs, compared to the other nanoparticles tested. These increased interactions in the presence of surface-bound ssDNA oligos, including $\mathrm{CpG}$, appear to operate through multiple mechanisms. Further, CpG-PEG-E2 also demonstrated increased LN retention over $48 \mathrm{hr}$, and less presence in blood draining organs, compared to the E2 and mPEG-E2 nanoparticles. Overall, these results demonstrate that decoration of protein-based nanoparticles with $\mathrm{CpG}$ can increase lymph node retention and uptake by APCs, factors that are beneficial in vaccine design.

\section{Supplementary Material}

Refer to Web version on PubMed Central for supplementary material.

\section{Acknowledgments}

We gratefully acknowledge Prof. Aaron Esser-Kahn for use of his flow cytometer, Prof. Wendy Liu and Dr. Yoon Kim for macrophages, and Prof. Nilabh Shastri for B3Z T cells. DLS was carried out at the UCI Laser Spectroscopy Facility. This work was supported by the National Institutes of Health (R21EB017995), the National Cancer Institute of the National Institutes of Health (P30CA062203), and the University of California Cancer Research Coordinating Committee (UCCRCC-101868).

\section{References}

1. Aly HA. Cancer therapy and vaccination. Journal of Immunological Methods. 2012; 382(1-2):1-23. [PubMed: 22658969]

2. Romero P, Banchereau J, Bhardwaj N, Cockett M, Disis ML, Dranoff G, Gilboa E, Hammond SA, Hershberg R, Korman AJ, Kvistborg P, Melief C, Mellman I, Palucka AK, Redchenko I, Robins H, Sallusto F, Schenkelberg T, Schoenberger S, Sosman J, Tureci O, Van den Eynde B, Koff W, Coukos G. The Human Vaccines Project: A roadmap for cancer vaccine development. Science Translational Medicine. 2016; 8(334):334ps9.

3. Bachmann MF, Jennings GT. Vaccine delivery: a matter of size, geometry, kinetics and molecular patterns. Nat Rev Immunol. 2010; 10(11):787-96. [PubMed: 20948547] 
4. Palucka K, Banchereau J. Cancer immunotherapy via dendritic cells. Nature Reviews. Cancer. 2012; 12(4):265-77. [PubMed: 22437871]

5. Shukla S, Steinmetz NF. Emerging nanotechnologies for cancer immunotherapy. Experimental Biology and Medicine. 2016

6. Gu L, Mooney DJ. Biomaterials and emerging anticancer therapeutics: engineering the microenvironment. Nature Reviews. Cancer. 2016; 16(1):56-66. [PubMed: 26694936]

7. Aktas Y, Yemisci M, Andrieux K, Gursoy RN, Alonso MJ, Fernandez-Megia E, Novoa-Carballal R, Quinoa E, Riguera R, Sargon MF, Celik HH, Demir AS, Hincal AA, Dalkara T, Capan Y, Couvreur P. Development and brain delivery of chitosan-PEG nanoparticles functionalized with the monoclonal antibody OX26. Bioconjugate Chemistry. 2005; 16(6):1503-11. [PubMed: 16287248]

8. Cruz LJ, Tacken PJ, Fokkink R, Figdor CG. The influence of PEG chain length and targeting moiety on antibody-mediated delivery of nanoparticle vaccines to human dendritic cells. Biomaterials. 2011; 32(28):6791-803. [PubMed: 21724247]

9. Ueno H, Klechevsky E, Schmitt N, Ni L, Flamar AL, Zurawski S, Zurawski G, Palucka K, Banchereau J, Oh S. Targeting human dendritic cell subsets for improved vaccines. Seminars in Immunology. 2011; 23(1):21-27. [PubMed: 21277223]

10. Lahoud MH, Ahmet F, Zhang JG, Meuter S, Policheni AN, Kitsoulis S, Lee CN, O'Keeffe M, Sullivan LC, Brooks AG, Berry R, Rossjohn J, Mintern JD, Vega-Ramos J, Villadangos JA, Nicola NA, Nussenzweig MC, Stacey KJ, Shortman K, Heath WR, Caminschi I. DEC-205 is a cell surface receptor for CpG oligonucleotides. Proc Natl Acad Sci U S A. 2012; 109(40):16270-5. [PubMed: 22988114]

11. Dalmau M, Lim S, Chen HC, Ruiz C, Wang SW. Thermostability and molecular encapsulation within an engineered caged protein scaffold. Biotechnol Bioeng. 2008; 101(4):654-64. [PubMed: 18814295]

12. Molino NM, Anderson AK, Nelson EL, Wang SW. Biomimetic protein nanoparticles facilitate enhanced dendritic cell activation and cross-presentation. ACS Nano. 2013; 7(11):9743-52. [PubMed: 24090491]

13. Molino NM, Bilotkach K, Fraser DA, Ren D, Wang SW. Cell Uptake and Complement Responses Toward Polymer-Functionalized Protein Nanocapsules. Biomacromolecules. 2012; 13(4):974-981. [PubMed: 22416762]

14. Molino NM, Neek M, Tucker JA, Nelson EL, Wang SW. Viral-mimicking protein nanoparticle vaccine for eliciting anti-tumor responses. Biomaterials. 2016; 86:83-91. [PubMed: 26894870]

15. Ren D, Kratz F, Wang SW. Protein nanocapsules containing doxorubicin as a pH-responsive delivery system. Small. 2011; 7(8):1051-60. [PubMed: 21456086]

16. Ren D, Kratz F, Wang SW. Engineered drug-protein nanoparticle complexes for folate receptor targeting. Biochemical Engineering Journal. 2014; 89:33-41. [PubMed: 25018664]

17. Molino NM, Wang SW. Caged protein nanoparticles for drug delivery. Current Opinion in Biotechnology. 2014; 28:75-82. [PubMed: 24832078]

18. Plummer EM, Manchester M. Viral nanoparticles and virus-like particles: platforms for contemporary vaccine design. Wiley Interdisciplinary Reviews-Nanomedicine and Nanobiotechnology. 2011; 3(2):174-196. [PubMed: 20872839]

19. Wen AM, Le N, Zhou X, Steinmetz NF, Poplcin DL. Tropism of CPMV to Professional Antigen Presenting Cells Enables a Platform to Eliminate Chronic Infections. ACS Biomater-Sci Eng. 2015; 1(11):1050-1054. [PubMed: 27280157]

20. Utaisincharoen P, Kespichayawattana W, Anuntagool N, Chaisuriya P, Pichyangkul S, Krieg AM, Sirisinha S. CpG ODN enhances uptake of bacteria by mouse macrophages. Clinical and Experimental Immunology. 2003; 132(1):70-5. [PubMed: 12653838]

21. Reinis M, Stepanek I, Simova J, Bieblova J, Pribylova H, Indrova M, Bubenik J. Induction of protective immunity against MHC class I-deficient, HPV16-associated tumours with peptide and dendritic cell-based vaccines. International Journal of Oncology. 2010; 36(3):545-51. [PubMed: 20126973]

22. Askew D, Chu RS, Krieg AM, Harding CV. CpG DNA induces maturation of dendritic cells with distinct effects on nascent and recycling MHC-II antigen-processing mechanisms. Journal of Immunology. 2000; 165(12):6889-95. 
23. Switaj T, Jalili A, Jakubowska AB, Drela N, Stoksik M, Nowis D, Basak G, Golab J, Wysocki PJ, Mackiewicz A, Sasor A, Socha K, Jakobisiak M, Lasek W. CpG immunostimulatory oligodeoxynucleotide 1826 enhances antitumor effect of interleukin 12 gene-modified tumor vaccine in a melanoma model in mice. Clinical Cancer Research: an official journal of the American Association for Cancer Research. 2004; 10(12 Pt 1):4165-75. [PubMed: 15217954]

24. Milley B, Kiwan R, Ott GS, Calacsan C, Kachura M, Campbell JD, Kanzler H, Coffman RL. Optimization, Production, and Characterization of a CpG-Oligonucleotide-Ficoll Conjugate Nanoparticle Adjuvant for Enhanced Immunogenicity of Anthrax Protective Antigen. Bioconjugate Chemistry. 2016; 27(5):1293-304. [PubMed: 27074387]

25. Jokerst JV, Lobovkina T, Zare RN, Gambhir SS. Nanoparticle PEGylation for imaging and therapy. Nanomedicine (Lond). 2011; 6(4):715-28. [PubMed: 21718180]

26. Steinmetz NF, Manchester M. PEGylated viral nanoparticles for biomedicine: the impact of PEG chain length on VNP cell interactions in vitro and ex vivo. Biomacromolecules. 2009; 10(4):78492. [PubMed: 19281149]

27. Patel PC, Giljohann DA, Daniel WL, Zheng D, Prigodich AE, Mirkin CA. Scavenger receptors mediate cellular uptake of polyvalent oligonucleotide-functionalized gold nanoparticles. Bioconjugate Chemistry. 2010; 21(12):2250-6. [PubMed: 21070003]

28. Areschoug T, Gordon S. Scavenger receptors: role in innate immunity and microbial pathogenesis. Cellular Microbiology. 2009; 11(8):1160-9. [PubMed: 19388903]

29. West MA, Wallin RP, Matthews SP, Svensson HG, Zaru R, Ljunggren HG, Prescott AR, Watts C. Enhanced dendritic cell antigen capture via toll-like receptor-induced actin remodeling. Science. 2004; 305(5687):1153-7. [PubMed: 15326355]

30. Xiao K, Li Y, Luo J, Lee JS, Xiao W, Gonik AM, Agarwal RG, Lam KS. The effect of surface charge on in vivo biodistribution of PEG-oligocholic acid based micellar nanoparticles. Biomaterials. 2011; 32(13):3435-46. [PubMed: 21295849]

31. He C, Hu Y, Yin L, Tang C, Yin C. Effects of particle size and surface charge on cellular uptake and biodistribution of polymeric nanoparticles. Biomaterials. 2010; 31(13):3657-66. [PubMed: 20138662]

32. Shirota H, Tross D, Klinman DM. CpG Oligonucleotides as Cancer Vaccine Adjuvants. Vaccines. 2015; 3(2):390-407. [PubMed: 26343193]

33. Jain A, Jain SK. PEGylation: an approach for drug delivery, A review. Crit Rev Ther Drug Carrier Syst. 2008; 25(5):403-47. [PubMed: 19062633]

34. O'Riordan CR, Song A. PEGylated adenovirus for targeted gene therapy. Methods Mol Biol. 2008; 434:133-60. [PubMed: 18470643]

35. Yao X, Yoshioka Y, Morishige T, Eto Y, Watanabe H, Okada Y, Mizuguchi H, Mukai Y, Okada N, Nakagawa S. Systemic administration of a PEGylated adenovirus vector with a cancer-specific promoter is effective in a mouse model of metastasis. Gene Ther. 2009; 16(12):1395-404. [PubMed: 19641532]

36. Liu H, Moynihan KD, Zheng Y, Szeto GL, Li AV, Huang B, Van Egeren DS, Park C, Irvine DJ. Structure-based programming of lymph-node targeting in molecular vaccines. Nature. 2014; 507(7493):519-22. [PubMed: 24531764]

37. Cantisani R, Pezzicoli A, Cioncada R, Malzone C, De Gregorio E, D’Oro U, Piccioli D. Vaccine adjuvant MF59 promotes retention of unprocessed antigen in lymph node macrophage compartments and follicular dendritic cells. Journal of Immunology. 2015; 194(4):1717-25.

38. Olson MR, McDermott DS, Varga SM. The initial draining lymph node primes the bulk of the CD8 $\mathrm{T}$ cell response and influences memory $\mathrm{T}$ cell trafficking after a systemic viral infection. PLoS Pathog. 2012; 8(12):e1003054. [PubMed: 23236277]

39. Kourtis IC, Hirosue S, de Titta A, Kontos S, Stegmann T, Hubbell JA, Swartz MA. Peripherally administered nanoparticles target monocytic myeloid cells, secondary lymphoid organs and tumors in mice. PLoS One. 2013; 8(4):e61646. [PubMed: 23626707]

40. Manolova V, Flace A, Bauer M, Schwarz K, Saudan P, Bachmann MF. Nanoparticles target distinct dendritic cell populations according to their size. European Journal of Immunology. 2008; 38(5): 1404-13. [PubMed: 18389478] 
A

\begin{tabular}{|l|c|c|}
\hline Sample & Size $(\mathbf{n m})$ & Zeta $(\mathbf{m V})$ \\
\hline E2 & $29.1 \pm 1.3$ & $-12 \pm 1$ \\
\hline mPEG-E2 & $30.4 \pm 0.8$ & $-7 \pm 0.5$ \\
\hline CpG-PEG-E2 & $32.0 \pm 0.8$ & $-18 \pm 0.7$ \\
(non-CpG)-PEG-E2 & $31.4 \pm 0.7$ & $-16 \pm 1.4$ \\
\hline
\end{tabular}

Figure 1.

Hydrodynamic diameter size and surface charge characterization of nanoparticles. A)

Representative size distribution for E2, mPEG-E2, CpG-PEG-E2, and (non-CpG)-PEG-E2 nanoparticles. B) Average size and measured zeta potential of nanoparticles. 


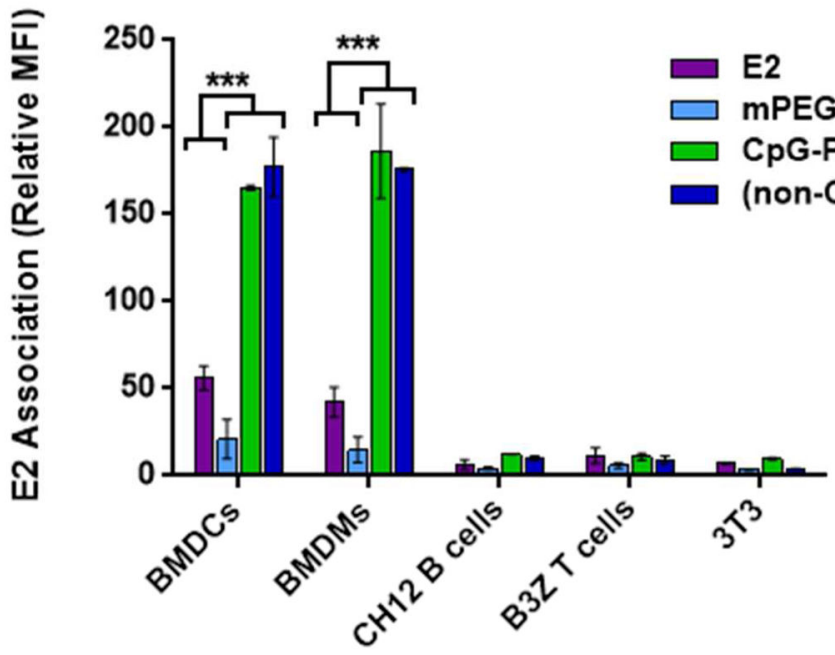

Figure 2.

BMDCs and BMDMs show increased association with CpG-PEG-E2 and (non-CpG)-PEGE2 nanoparticles in vitro, compared to their interactions with E2 and mPEG-E2. Cellular association was measured by mean fluorescence intensity (MFI) of cells incubated with 5 $\mathrm{Og} / \mathrm{mL}$ E2 nanoparticle for $1 \mathrm{hr}$ at $37^{\circ} \mathrm{C}$. Data is reported as average \pm S.E.M., relative to cellular background fluorescence (PBS), of 3 independent experiments. Statistical significance was determined with one-way ANOVA using a post-hoc Tukey's test (*** p < 0.001). 
A

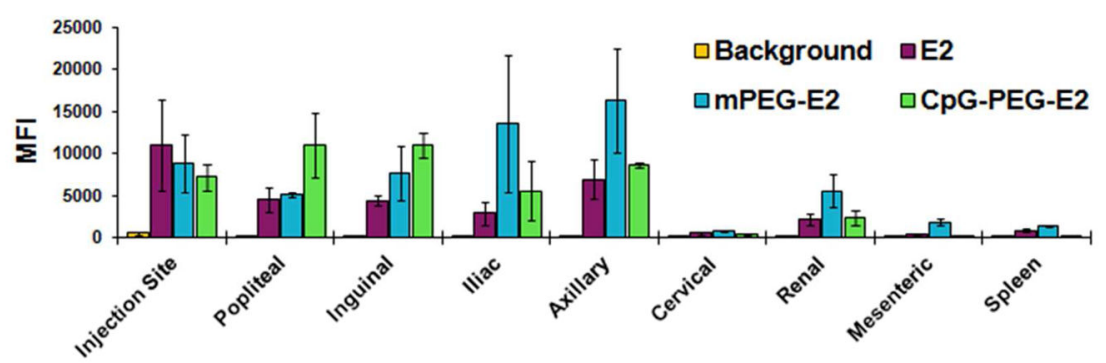

B

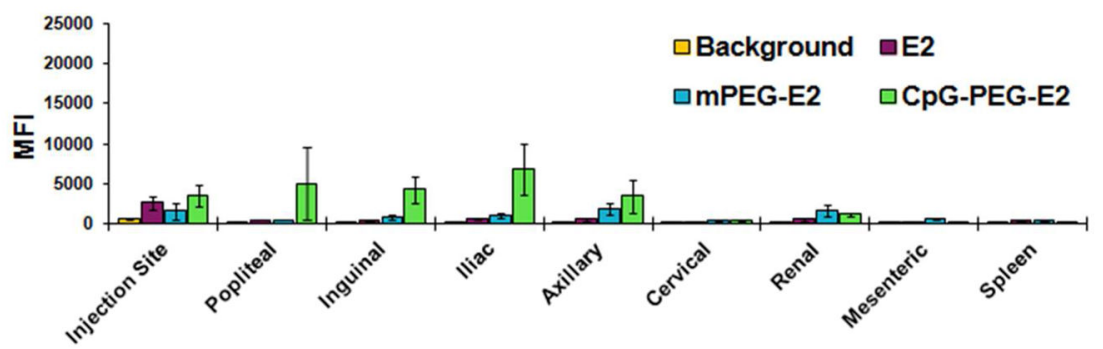

Figure 3.

Distribution of nanoparticles in the lymph nodes ipsilateral to injection site, mesenteric lymph node, and spleen following injection, after (A) 6 hours and (B) 48 hours. E2, mPEGE2, and CpG-PEG-E2 nanoparticles were administered subcutaneously. Mean fluorescence (MFI) was measured by flow cytometry of cells from relevant tissues, and background is tissue MFI from PBS-injected mice. Data is presented as average \pm S.E.M. of 3 independent experiments. 
A

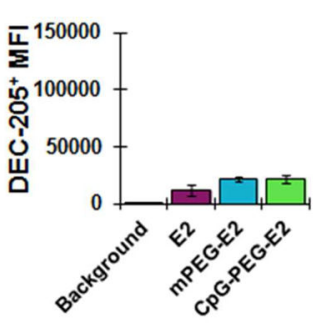

B

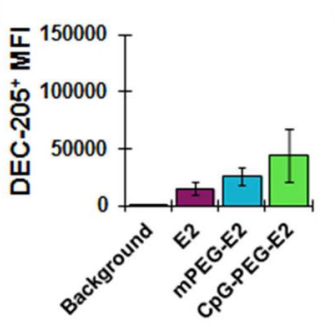

C

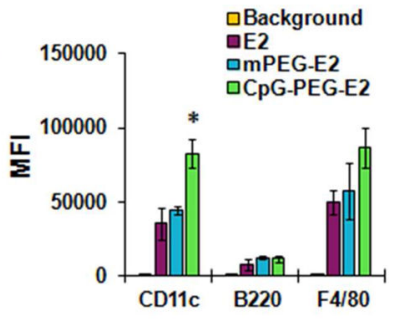

Figure 4.

Nanoparticle accumulation and uptake by cells in draining lymph nodes. The MFI of DEC-205 ${ }^{+}$cells in draining lymph nodes was determined A) $6 \mathrm{hr}$ or B) $48 \mathrm{hr}$ following subcutaneous administration of nanoparticles. E2 shows no significant preference for association with DEC-205 ${ }^{+}$cells in vivo following surface functionalization with PEG or CpG. Data is reported as average \pm S.E.M. of 3 independent experiments. C) Extent of nanoparticle association/uptake was measured by MFI of fluorescent-positive draining lymph node cells using flow cytometry $6 \mathrm{hr}$ following subcutaneous administration. CD11c, B220, and F4/80 markers generally indicate dendritic cells, B cells, and macrophages/ Langerhans DCs, respectively. Data is reported as average \pm S.E.M. of 3 independent experiments. Statistical significance within a group was determined using a one-way ANOVA followed by a post hoc Tukey's test, comparing all means $(* \mathrm{p}<0.05)$. 